\section{Optimization of In Vitro Regeneration from Leaf Explants of Apple Cultivars Golden Delicious and Melrose}

\author{
Nevena Mitić1, Mariana Stanišić, Jelena Milojević, Ljiljana Tubić, \\ Tatjana Ćosić, Radomirka Nikolić, and Slavica Ninković \\ Institute for Biological Research "Sinisa Stankovic,'” University of Belgrade, \\ Despot Stefan Boulevard 142, 11000 Belgrade, Serbia \\ Rade Miletić \\ Fruit Research Institute, Kralja Petra I/9, 32000 Čačak, Serbia
}

Additional index words. Malus domestica, organogenesis, pre-incubation in the dark, gelling agent, shoot multiplication

\begin{abstract}
An efficient in vitro shoot regeneration method from leaf explants of apple cultivars Golden Delicious and Melrose by optimization of regeneration medium, explant type and orientation, dark pre-treatment, and gelling agent is presented. Murashige and Skoog's regeneration medium containing $22 \mu \mathrm{M}$ thidiazuron (TDZ) and $1.5 \mu \mathrm{M}$ indole3-butyric acid (IBA) (M2 medium) was superior for regeneration as well as for subsequent shoot multiplication in both cultivars, providing regeneration frequency of $\mathbf{9 5 \%}$ or higher in the best combination with other factors. Pre-incubation in the dark proved to be an essential factor for regeneration. The use of agar as a gelling agent provides satisfactory regeneration frequency compared with media gelled with Phytagel $^{\mathrm{TM}}$. Leaf explants of cv. Melrose with adaxial surface in contact with M2 medium and those of cv. Golden Delicious orientated contrary regenerated the highest mean number of shoots per explant. Under optimal conditions, a maximal index of shoot-forming capacity of 11.44 and 6.30 for 'Melrose' and 'Golden Delicious', respectively, was achieved. Regenerated shoots were successfully rooted and acclimated ex vitro.
\end{abstract}

'Golden Delicious' and 'Melrose' are two economically important apple (Malus domestica Borkh.) cultivars grown worldwide. 'Golden Delicious' is the main apple cultivar of the 20th century, both as a commercial variety and as breeding stock for many other varieties. 'Melrose', a 'Jonathan' $\times$ 'Red Delicious' cross, is also an attractive apple cultivar with fruits of very high quality, suitable for fresh eating as well as for cooking purposes. Besides their good growing and fruit characteristics, both cultivars are highly susceptible to various diseases including those vectored by insects. The genetic improvement of Malus species has been mainly achieved by conventional plant breeding methods that recombined the desired genes from fruit tree varieties and related species by sexual hybridization into new cultivars with desirable traits. However, this is a slow process that may result in the loss of many favorable traits. Improvement of stress and pest tolerance traits by genetic engineering, without disrupting the otherwise desirable genetic characteristics, is a viable alternative to the use of traditional breeding techniques that would benefit both consumers and the

\footnotetext{
Received for publication 14 Mar. 2012. Accepted for publication 25 May 2012.

The Ministry of Education and Science of the Republic of Serbia, Grant No. ON173015 supported this work.

${ }^{1}$ To whom reprint requests should be addressed; e-mailmitic.nevena@ibiss.bg.ac.rs.
}

environment. A prerequisite to achieving successful genetic transformation in apple is the development of an efficient regeneration system that would increase adventitious shoot regeneration, because the regeneration ability of transformed tissues is much lower than that of non-transformed ones (Pawlicki-Jullian et al., 2002). Although a number of regeneration protocols for apple have been published, mainly for various apple rootstocks and several cultivars (reviewed by Bhatti and Jha, 2010; Dobránszki and Teixeira da Silva, 2010; Magyar-Tábori et al., 2010), the regeneration potential was strongly genotype-dependent and needs optimization for each individual genotype, explant type, and culture stage. Adventitious shoot regeneration in 'Golden Delicious' was previously achieved with a frequency of $\approx 25 \%$ to $60 \%$ (Dufour, 1990 ; Durham and Korban, 1994; Korban et al., 1992; Viršček-Marn et al., 1999). To our knowledge, no previous research protocols included the cultivar 'Melrose'. The present study was conducted to optimize in vitro shoot regeneration from leaf explants of the apple cultivar Golden Delicious and to establish an efficient in vitro shoot regeneration system for 'Melrose' as a prerequisite for successful genetic transformation aimed at incorporating genes for insecticidal proteins. The effects of the regeneration medium, explant type and orientation, dark pretreatment, gelling agent, and ethylene inhibitors on regeneration efficiency were studied. The influence of regeneration medium on subsequent shoot proliferation was also evaluated.
Plant material and establishment of aseptic axillary shoot cultures. Branches up to $50 \mathrm{~cm}$ in length were collected from 1-yearold increments of 15-year-old apple tree cultivars Golden Delicious and Melrose grown in the apple tree collection orchard of the Institute for Fruit Research in Čačak, Serbia, in Mar. 2009 and 2010. The twigs containing dormant vegetative buds were stored in water in the culture room for 2 weeks until the buds reached 0.8 to $1.5 \mathrm{~cm}$ in length. Excised buds were rinsed with sterile distilled water with a few drops of detergent (Fairy; Procter and Gamble) for $10 \mathrm{~min}$, then immersed in 5\% commercial bleach $(4 \% \mathrm{NaOCl})$ for $20 \mathrm{~min}$, and rinsed five times with sterile deionized water. To establish aseptic cultures, the shoot apex with one pair of primordial leaves was excised aseptically from buds and cultured for 4 weeks in $100-\mathrm{mL}$ Erlenmeyer flasks containing $40 \mathrm{~mL}$ of Murashige and Skoog (1962) medium (MS) with $3 \%(\mathrm{w} / \mathrm{v})$ sucrose, $0.7 \%(\mathrm{w} / \mathrm{v})$ agar (Torlak, Belgrade, Serbia), $100 \mathrm{mg} \cdot \mathrm{L}^{-1}$ myo-inositol, $5 \mu \mathrm{M}$ 6-benzylaminopurine (BA), and $0.5 \mu \mathrm{M}$ and 1-naphthaleneacetic acid (NAA). Shoots were transferred to shoot multiplication medium (SM) containing MS salts and vitamins, $3 \%(\mathrm{w} / \mathrm{v})$ sucrose, $0.7 \%(\mathrm{w} / \mathrm{v})$ agar, $100 \mathrm{mg} \cdot \mathrm{L}^{-1}$ myo-inositol, $2.2 \mu \mathrm{M}$ BA, and $0.26 \mu \mathrm{M}$ NAA. The $\mathrm{pH}$ of the media was adjusted to 5.8 before autoclaving at $114{ }^{\circ} \mathrm{C}$ and $0.9 \mathrm{kPa}$ for $25 \mathrm{~min}$. Occasionally, the cultures were suffused with $5 \mathrm{~mL}$ of liquid SM medium and subcultured at 4-week intervals to obtain a sufficient amount of stock shoot cultures for regeneration experiments. Cultures were maintained in a growth chamber at $25 \pm 2{ }^{\circ} \mathrm{C}$ under a 16 -h light photoperiod provided by cool-white fluorescent tubes $\left(45 \mu \mathrm{mol} \cdot \mathrm{m}^{-2} \cdot \mathrm{s}^{-1}\right)$.

General protocol for shoot regeneration from leaf explants. Healthy and fully expanded young leaves (5 to $8 \mathrm{~mm}$ in length) collected from the upper third of in vitro shoots propagated on SM medium for 4 weeks were used as initial explants for regeneration experiments. Leaves were cut transversely across the midrib into three pieces proximal, middle, and distal designated as 1, 2, and 3, respectively, and placed into petri dishes $(90 \times 10 \mathrm{~mm}, 25 \mathrm{~mL}$ of medium) with either the adaxial or abaxial surface in contact with the medium M1, M2, or M3. All media consisted of MS basal salts and vitamins, $3 \%(\mathrm{w} / \mathrm{v})$ sucrose, $0.7 \%(\mathrm{w} / \mathrm{v})$ agar, and $100 \mathrm{mg} \cdot \mathrm{L}^{-1}$ myo-inositol. M1 was supplemented with $3 \mu \mathrm{M} \mathrm{TDZ}$ and $5 \mu \mathrm{MNAA}$ (Maheswaran et al., 2007), M2 with $22 \mu \mathrm{M}$ TDZ and $1.5 \mu \mathrm{M}$ IBA (Seong and Song, 2008). M3 callus induction medium contained $10 \mu \mathrm{M}$ TDZ and $2.65 \mu \mathrm{M}$ NAA, whereas M3 shoot induction medium was supplemented with $1 \mu \mathrm{M}$ NAA and $4.4 \mu \mathrm{M}$ BA (Smolka et al., 2009).

Preliminary experiment. In a preliminary experiment, the effect of light/dark conditions, gelling agent, ethylene inhibitor silver thiosulfate (STS), and medium used was examined to determine the basic conditions for regeneration. Regeneration frequency was assessed after 6 weeks of culture. 
Effect of light-dark pretreatments. Leaf segments placed on M1, M2, and M3 regeneration media were pre-treated with either a 16-h photoperiod or complete darkness for 3 weeks before transferring to a 16-h photoperiod. To assess the impact of light-dark pre-treatments, three petri dishes, with 30 leaf explants (15 adaxial +15 abaxial) each, were prepared for each of the treatments (light or dark) for each medium (M1, M2, and M3). The experiment was repeated once.

Effect of gelling agent. Young expanding leaves from shoots cultured on SM medium were placed onto regeneration media gelled with $0.7 \%$ agar or $0.25 \%$ gellan gum (Sigma Phytagel $^{\mathrm{TM}}$ Cat. No. P8169). For each gelling agent, two petri dishes containing 30 leaf explants ( 15 adaxial +15 abaxial) for each medium (M1 and M2) were used and the experiment was repeated twice.

Effect of ethylene inhibitors. Leaves of 'Golden Delicious' and 'Melrose' shoots were cultured on M1 and M2 regeneration media supplemented with $0,30,60$, or $120 \mu \mathrm{M}$ STS. STS stock solution was prepared by mixing a $0.465 \mathrm{~mm} \mathrm{AgNO}_{3}$ solution with a $1.865 \mathrm{~mm}$ $\mathrm{NaS}_{2} \mathrm{O}_{3}$ solution (ratio 1:4) following procedures described by Burgos and Alburquerque (2003). STS was filter-sterilized and added to the culture medium after autoclaving. Each treatment was performed in two petri dishes containing 30 leaf explants (15 adaxial +15 abaxial) for each medium used (M1 and M2) and the experiment was repeated twice.

In preliminary experiments, the influence of media, gelling agent, and STS on regeneration frequency was assessed after 6 weeks of culture on M1-M3 media.

Regeneration experiment. After preliminary tests, in a further regeneration experiment, the influence of cultivar, medium, and explant orientation was studied. Explants were cultured on M1 and M2 regeneration medium using agar as a gelling agent and a 3-week dark pretreatment. For shoot regeneration, two petri dishes were evaluated for each treatment with 15 adaxially and 15 abaxially placed leaf segments per dish $(n=30)$. The experiment was repeated twice. Data collected from these experiments included callus formation, regeneration frequency, and the number of shoots per explant. Regeneration frequency was presented as the percentage of explants that produced at least one shoot assessed after 6 weeks of culture on regeneration media M1 and M2. Mean number of shoots per explant was calculated as the total number of regenerated shoots recorded after 8 weeks of culture on regeneration media divided by the number of regenerating explants in each replicate. An index of shoot-forming capacity (SFC) was used to evaluate cumulative effects of the mean shoot number and frequency of regeneration and was calculated as follows: $\mathrm{SFC}=$ (mean number of shoots per regenerating leaf section $) \times(\%$ of regenerating sections $) \div 100$.

Multiplication of regenerated shoots, rooting, and acclimatization. Shoots $(\approx 5$ to $8 \mathrm{~mm}$ long) regenerated from leaf segments on M1 and M2 medium were separated and transferred onto SM medium for 6 weeks. After this period, when shoots attained a 2 to $3 \mathrm{~cm}$ length, multiplication rate was calculated on the basis of the number of propagules derived from one shoot cluster. Necrotic and decayed shoots were removed from the clusters before transferring to fresh medium. For shoot multiplication, each treatment consisted of five replicates with five samples $(n=25)$.

Healthy and green shoots were separated from shoot clusters and placed individually on rooting MS medium with IBA or NAA at 0 , $2.5,5$, or $10 \mu \mathrm{M}$. Ten shoots in two replicates were evaluated in each rooting treatment. Cultures were initially kept in the dark for $5 \mathrm{~d}$ followed by $2 \mathrm{~d}$ of a $16-\mathrm{h}$ photoperiod, after which the shoots were transferred onto plant growth regulator (PGR)-free MS medium and cultured in the light for 4 to 6 weeks until roots reached an $\approx 3-7$-cm length.

Rooted plantlets were rinsed with running tap water to remove adhered agar and then transferred to plastic pots $(50 \times 14 \times 16 \mathrm{~cm})$ containing a soil-sand 3:1 (v/v) mixture. The pots with plants were covered with glass panel to preserve high moisture and cultivated in a greenhouse. After 2 weeks the glass covering was removed and the plantlets were cultivated under greenhouse conditions $\left(27^{\circ} \mathrm{C}\right.$ day, $20^{\circ} \mathrm{C}$ night, 16 -h daylength, and $70 \%$ relative humidity) with occasional watering for another 2 months.

Statistical analysis. In all treatments, cultures were placed in a completely randomized design. Percentage data were subjected to angular transformation and mean shoot number data to square root transformation before analysis. The data were subjected to standard factorial analysis of variance. For shoot regeneration, the means were separated using Fisher's least significant difference test at $P \leq 0.05$, whereas for shoot multiplication, $t$ test was used. For presentation, the data were inversely transformed.

\section{Results and Discussion}

Preliminary experiments. Preliminary experiments were performed to postulate the basic conditions for efficient regeneration from leaf explants of 'Golden Delicious' and 'Melrose'. The parameters known to generally affect shoot regeneration in fruit tree species were evaluated, including light or dark conditions, gelling agent, and ethylene inhibitor in three media indicated as optimal for regeneration of other apple cultivars (Maheswaran et al., 2007; Seong and Song, 2008) and apple rootstock M26 (Smolka et al., 2009). We found that $46.7 \%$ of adaxial explants and $75.0 \%$ of abaxial explants of 'Melrose' and $62.7 \%$ of both adaxial and abaxial explants of 'Golden Delicious' cultured under light conditions produced calli independently of the culture medium used. These green or green-red calli were compact, hard, and never produced shoots. After prolonged incubation in the light, the explants became brownish and finally died. However, almost $100 \%$ of dark-pretreated explants of both cultivars produced calli mainly formed on cut edges of explants or along the midribs. Calli induced on M1 and $\mathrm{M} 2$ medium were small-sized $(\approx 3 \times 3 \mathrm{~mm})$, spongy, and pale green. Prior incubation in the dark proved to be a key factor for regeneration from leaf explants in both 'Golden Delicious' and 'Melrose'. The dark treatment was reported to promote organogenesis in various fruit tree species, including apple (Famiani et al., 1994; Fasolo et al., 1989; Liu et al., 1983; MagyarTábori et al., 2010; Predieri and Fasolo, 1989), because it can increase the endogenous auxin levels (Korban et al., 1992; Miguel et al., 1996) and reduce the cell wall thickness thus facilitating translocation of PGRs (Herman and Hess, 1963). Recently, Dobránszki and Teixeira da Silva (2011) have reported that light delayed callus formation from thin cell layers in two apple cultivars, Royal gala and Freedom, but the effect on shoot regeneration ability was strongly influenced by genotype and in difficultto-regenerate cultivar Freedom shoot development was completely inhibited by light.

The calli of 'Golden Delicious' and 'Melrose' started to regenerate buds even during the induction period in the dark. A week after transfer to the light, small globular or leafy shoots were clearly visible on the calli (Fig. 1A), whereas some were formed directly from leaf tissue (Fig. 1B). Direct organogenesis from apple tissues was earlier reported by Belaizi et al. (1991), Dufour (1990), and Pawlicki and Welander (1994).

In both 'Melrose' and 'Golden Delicious', regardless of the orientation of the explants, $\approx 50 \%$ of all explants cultured on M1 medium for 6 weeks were regenerative, whereas significantly higher regeneration frequency was recorded in explants cultured on M2 medium $(71.3 \%$ and $82.7 \%$, respectively). Obtained regeneration frequencies are comparable with the range of the higher frequencies reported for different apple cultivars (see review by Magyar-Tábori et al., 2010). Calli formed on leaf explants cultured on M3 callus induction medium were significantly more voluminous than those induced on M1 and M2 media, soft and whitish. On transfer onto M3 regeneration medium, explants did not form shoots, regardless of photoperiod regime. Thus, M3 medium was shown to be unfavorable for shoot induction of examined cultivars and was therefore excluded from further experimentation.

In addition to the dark regime, which was an essential factor for organogenesis, the regeneration frequency was affected by different gelling agents; agar vs. gellan gum (Phytagel ${ }^{\mathrm{TM}}$ ) was used (Fig. 2A-B). Contrary to reports in which gellan gum was a better choice concerning regeneration of fruit tree species (Abdollahi et al., 2006; Chevreau et al., 1997), in the present study, the highest regeneration frequencies in both 'Melrose' $(96.6 \%$, Fig. 2A) and 'Golden Delicious' (87.4\%, Fig. 2B) were achieved on M2 medium solidified with agar as the gelling agent. Agar also proved to be a better gelling agent for efficient transformation in 'Golden Delicious' (Sriskindarajah et al., 1994). Moreover, the use of gellan gum increased the occurrence of hyperhydricity from approximately threefold in 'Golden Delicious' $(16.5 \%$ on M1 and $22 \%$ on M2 compared with $5.0 \%$ and $7.5 \%$, respectively, on agar medium) up to almost $90 \%$ 


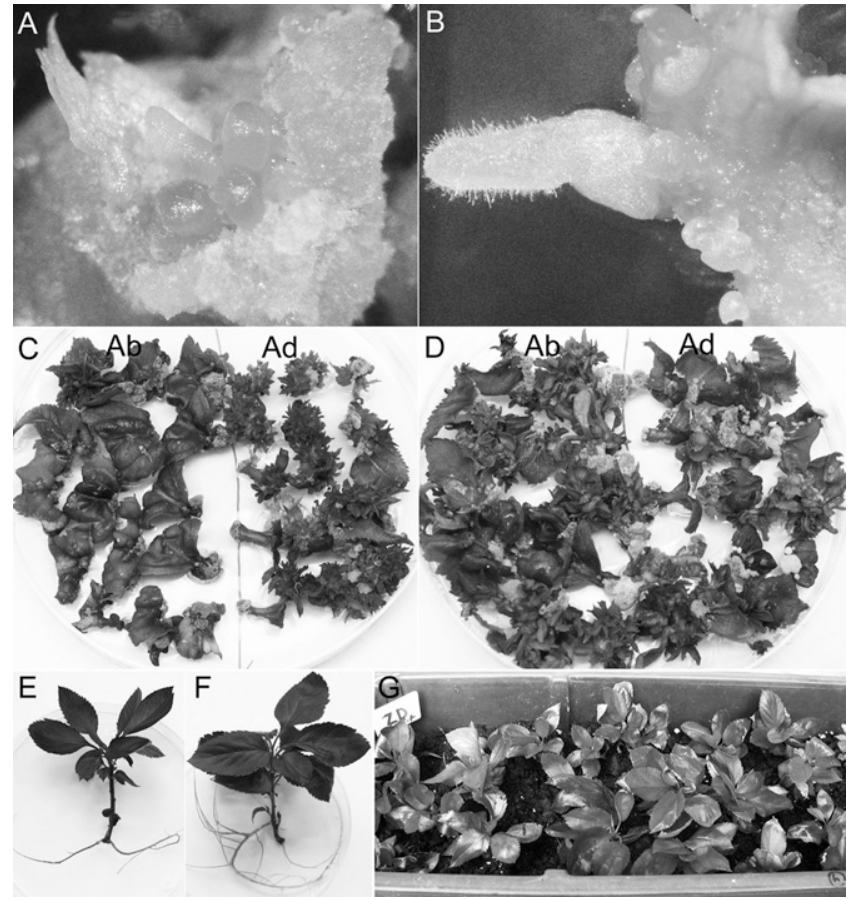

Fig. 1. Shoot induction and plant regeneration from leaf explants of apple cultivars Melrose and Golden Delicious (A) buds regenerating from callus tissue formed on 'Melrose' leaf explant cultivated on M2 medium when transferred to the light after 3 weeks of pre-incubation in dark; (B) buds formed directly on the adaxial surface of the 'Melrose' leaf explant; (C-D) regenerating shoots on the adaxial (Ad) and abaxial $(\mathrm{Ab})$ surface of the leaf explants of cv. Melrose (C) and Golden Delicious (D) after 8 weeks of culture on M2 medium; (E-F) rooted shoots of cv. Melrose (E) and Golden Delicious $(\mathbf{F})$ initially cultivated on MS medium with $10 \mu \mathrm{M}$ and $2.5 \mu \mathrm{M}$ IBA, respectively, after 6 weeks of culture on MS plant growth regulator-free medium; $(\mathbf{G})$ acclimatized plantlets cultivated in a greenhouse. $\mathrm{MS}=$ Murashige and Skoog; IBA = indole-3-butyric acid.

in 'Melrose'. A similar phenomenon of increasing hyperhydricity $(36.9 \%)$ of shoots regenerated on agar + Gerlite combination compared with agar medium $(0 \%)$ was obtained in 'Goldspur' apple cultivar (Viršček-Marn et al., 1999).

The addition of the ethylene inhibitor STS at $30 \mu \mathrm{M}$ did not have a significant effect on regeneration frequency in 'Melrose' on either M1 or M2 medium, whereas a slight increase in regeneration frequency of 'Golden Delicious' explants cultured on M1 medium was statistically insignificant (data not shown). A further increase of STS concentration up to $120 \mu \mathrm{M}$ decreased the frequency of regeneration in both apple cultivars.

Using agar as a gelling agent in combination with dark pretreatment, the regeneration in both cultivars Golden Delicious and Melrose was achieved when the same medium, M1 or M2, was used for both callus induction and shoot regeneration. Both media contained TDZ, which was reported as the most potent cytokinin for apple regeneration (MagyarTábori et al., 2010).

Regeneration from leaf explants using $M 1$ and M2 media. After preliminary tests, the influence of genotype, explant part, and orientation was assessed on M1 and M2 regeneration media using agar as the gelling agent and a 3-week dark pre-treatment to find the best combination for regeneration of each cultivar. After 3 weeks of culture in the dark, followed by 1 -week culture in the light, $95 \%$ to $100 \%$ of the explants of both cultivars produced calli on M1 and M2 media independently of the leaf part or its orientation (Table 1). After 6 weeks of culture on the regeneration medium, the percentage of regenerating calli designated as regeneration frequency was scored. According to analysis of variance (ANOVA) performed within the same cultivar, it depended on medium used and explant orientation in 'Melrose', whereas in 'Golden Delicious' medium, explant orientation as well as interaction of medium $\times$ explant orientation significantly affect this trait. For both cultivars, M2 medium was superior for frequency of regeneration, reaching nearly $100 \%$ in the best combinations (Table 1). However, the efficiency of regeneration depends not only on the medium used, but also on the orientation of explant on the culture media. Leaf explants can be cultured with either the abaxial or adaxial surface in contact with the medium (George, 1993) and differences between 'Golden Delicious' and 'Melrose' were found in explant orientation. The highest regeneration frequency (97.4\%) was achieved in cultivar Melrose when the leaf adaxial side was in contact with the culture medium (Fig. 1C), whereas in 'Golden Delicious', the best regeneration response in from explants oriented with the abaxial side down (Fig. 1D) (Table 1). According to Fisher's least significant difference test, no significant differences in regeneration frequency among the same percentage $(97.4 \%)$ was obtained leaf parts 1,2, and 3 were observed (Table 1). This observation is opposite to that reported by Yepes and Aldwinckle (1994) that the regeneration capacity increased dramatically from the tip toward the base of the leaf and was higher from the middle to the proximal end.

When cultivar was included in the ANOVA, this analysis indicated a strong influence of cultivar and culture medium on the mean number of shoots regenerated per explant. The regeneration was further influenced significantly by the explant orientation as well as by the interactions cultivar $\times$ explant orientation and cultivar $\times$ medium $\times$ explant orientation. The differences between cultivars were more pronounced when comparing the mean number of shoots regenerated per explant than regeneration frequencies. Performed within the same cultivar, ANOVA showed a significant effect of the same factors influenced regeneration frequency, i.e., medium and explant orientation for 'Melrose', and medium, explant orientation, and medium $\times$ explant orientation for 'Golden Delicious'. In cultivar Melrose, the highest number of shoots per explant was regenerated from leaf parts 1 and 2 (10.58 and 11.75 , respectively) with the adaxial surface in contact with M2 medium (Table 1). In 'Golden Delicious', the maximum number of shoots obtained from explants placed with the abaxial side in contact with the M2 medium was almost twice lower compared with cv. Melrose (Table 1). Consequently, the best SFC index ranged from 6.30 in 'Golden Delicious' up to 11.44 in 'Melrose'.

In both cultivars, M2 medium proved to be more effective for regeneration than M1, probably as a result of the higher concentration of TDZ contained in M2 $(22 \mu \mathrm{M})$ compared with M1 $(3 \mu \mathrm{M})$. The optimal TDZ concentration depended on genotype. Thus, 'Golden Delicious' and 'Melrose' can be classified into a group of apple cultivars that prefers higher levels (greater than $10.0 \mu \mathrm{M}$ ) of TDZ along with 'M7', 'Paladino Spur McIntosh', 'Macspur', 'Gala', and 'Strakrimson' (Magyar-Tábori et al., 2010). However, the efficiency was dependent on the cultivar and 'Golden Delicious' showed almost a twofold lower regeneration ability than 'Melrose'. Using the current protocol including M2 medium, successfully used in transformation of 'Fuji' apple plants (Seong and Song, 2008), the regeneration frequency of 'Golden Delicious' leaf explants was significantly improved (97.4\%) compared with previously reported protocols for the same cultivar (from $\approx 4 \%$ to $73 \%$ ) using MS medium supplemented with 10 or $25 \mu \mathrm{M}, 1 \mu \mathrm{M}$, $4 \mu \mathrm{M}$, and $0.91 \mu \mathrm{M}$ TDZ (Dufour, 1990; Theiler-Hedtrich and Theiler-Hedtrich, 1990; Korban et al., 1992; Viršček-Marn et al., 1999, respectively). Using modified MS regeneration medium containing $0.9 \mu \mathrm{M}$ TDZ and $0.5 \mu \mathrm{M}$ IBA, and by application of the two phosphatase inhibitors, Grafe and Wricke (1998) were able to improve the regeneration response of 'Golden Delicious' primary leaf explants only up to $70 \%$. Differences between our and previously published results may be the result of differences in the applied 

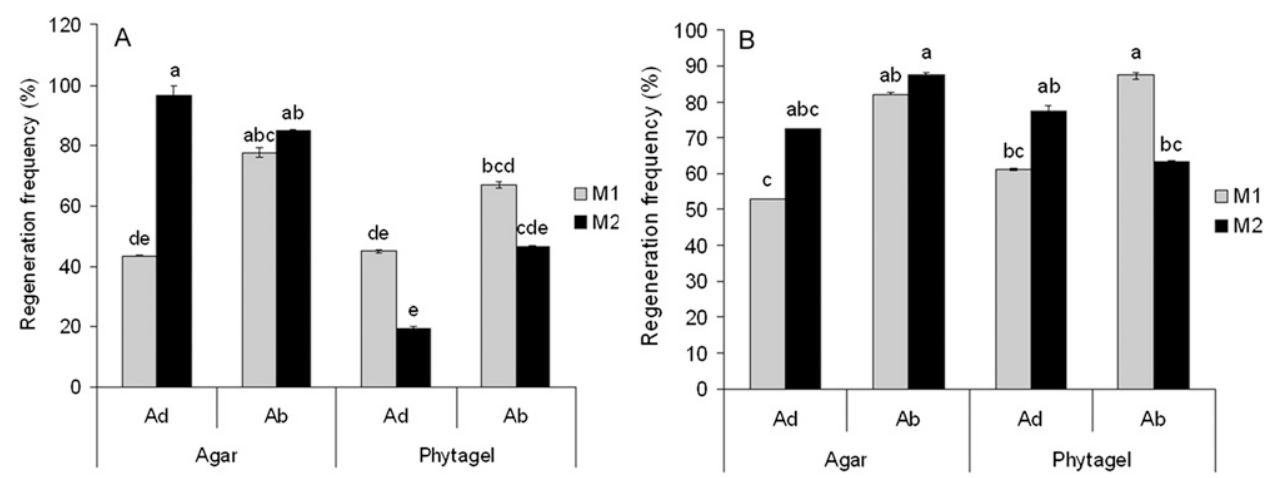

Fig. 2. Effect of gelling agent (Agar or Phytagel ${ }^{\mathrm{TM}}$ ) on frequency of adventitious shoot regeneration from adaxial (Ad) and abaxial (Ab) surface of leaf explants of 'Melrose' (A) and 'Golden Delicious' (B). The explants were cultured for 6 weeks on M1 or M2 regeneration media. The values are means ( \pm SE) of two replicates with 30 explants each. Different letters denote significant differences at $P \leq 0.05$ according to Fisher's least significant difference test.

Table 1. Effect of leaf fragments, orientation, and regeneration medium (M1 or M2) on callus formation and multiple shoot regeneration in apple cultivars Melrose and Golden Delicious. ${ }^{2}$

\begin{tabular}{|c|c|c|c|c|c|c|c|}
\hline Cultivar & Medium & $\begin{array}{c}\text { Explant } \\
\text { orientation }\end{array}$ & $\begin{array}{c}\text { Leaf } \\
\text { fragment }\end{array}$ & $\begin{array}{c}\text { Callus } \\
\text { formation }(\%)\end{array}$ & $\begin{array}{l}\text { Regeneration } \\
\text { frequency }(\%)\end{array}$ & $\begin{array}{c}\text { Mean no. of shoots } \\
\text { per explant }\end{array}$ & $\begin{array}{l}\text { Shoot-forming } \\
\text { capacity (SFC) }\end{array}$ \\
\hline \multirow{12}{*}{ Melrose } & M1 & $\mathrm{Ab}^{\mathrm{y}}$ & $1^{\mathrm{w}}$ & 100 & $18.4 \pm 1.8 \mathrm{c}$ & $0.28 \pm 0.04 \mathrm{e}$ & 0.05 \\
\hline & M1 & $\mathrm{Ab}$ & 2 & 95 & $44.8 \pm 2.3 \mathrm{bc}$ & $0.56 \pm 0.06 \mathrm{de}$ & 0.25 \\
\hline & M1 & $\mathrm{Ab}$ & 3 & 95 & $39.0 \pm 4.4 \mathrm{bc}$ & $0.75 \pm 0.07 \mathrm{cde}$ & 1.72 \\
\hline & M1 & $\mathrm{Ad}^{\mathrm{x}}$ & 1 & 100 & $75.2 \pm 0.3 \mathrm{ab}$ & $2.96 \pm 0.06 \mathrm{~b}$ & 2.23 \\
\hline & M1 & Ad & 2 & 100 & $75.2 \pm 0.3 \mathrm{ab}$ & $2.82 \pm 0.07 \mathrm{bc}$ & 2.12 \\
\hline & M1 & Ad & 3 & 95 & $65.1 \pm 0.3 \mathrm{abc}$ & $2.18 \pm 0.07 \mathrm{bcd}$ & 1.42 \\
\hline & M2 & $\mathrm{Ab}$ & 1 & 100 & $50.0 \pm 1.0 \mathrm{bc}$ & $4.99 \pm 0.17 \mathrm{~b}$ & 2.50 \\
\hline & M2 & $\mathrm{Ab}$ & 2 & 100 & $60.2 \pm 1.1 \mathrm{abc}$ & $2.71 \pm 0.11 \mathrm{bc}$ & 1.63 \\
\hline & M2 & $\mathrm{Ab}$ & 3 & 95 & $65.1 \pm 0.3 \mathrm{abc}$ & $4.06 \pm 0.13 \mathrm{~b}$ & 2.64 \\
\hline & M2 & Ad & 1 & 100 & $94.7 \pm 5.3 \mathrm{a}$ & $10.58 \pm 0.09 \mathrm{a}$ & 10.02 \\
\hline & M2 & Ad & 2 & 100 & $97.4 \pm 2.6 \mathrm{a}$ & $11.75 \pm 0.07 \mathrm{a}$ & 11.44 \\
\hline & M2 & Ad & 3 & 95 & $75.2 \pm 0.3 \mathrm{ab}$ & $4.99 \pm 0.12 b$ & 3.75 \\
\hline \multirow[t]{12}{*}{ Golden Delicious } & M1 & $\mathrm{Ab}$ & 1 & 95 & $70.0 \pm 0.0 \mathrm{bcd}$ & $1.27 \pm 0.04 \mathrm{cdef}$ & 0.89 \\
\hline & M1 & $\mathrm{Ab}$ & 2 & 100 & $39.8 \pm 1.1 \mathrm{~d}$ & $0.42 \pm 0.04 \mathrm{f}$ & 0.17 \\
\hline & M1 & $\mathrm{Ab}$ & 3 & 100 & $45.0 \pm 0.3 \mathrm{~cd}$ & $0.69 \pm 0.05$ ef & 0.31 \\
\hline & M1 & Ad & 1 & 100 & $50.0 \pm 0.0 \mathrm{~cd}$ & $1.05 \pm 0.06 \mathrm{def}$ & 0.53 \\
\hline & M1 & Ad & 2 & 100 & $44.8 \pm 2.3 \mathrm{~cd}$ & $0.45 \pm 0.03 \mathrm{f}$ & 0.20 \\
\hline & M1 & Ad & 3 & 100 & $55.0 \pm 0.3 \mathrm{bcd}$ & $0.74 \pm 0.05$ ef & 0.41 \\
\hline & M2 & $\mathrm{Ab}$ & 1 & 100 & $97.4 \pm 2.6 \mathrm{a}$ & $5.44 \pm 0.04 \mathrm{a}$ & 5.30 \\
\hline & M2 & $\mathrm{Ab}$ & 2 & 100 & $97.4 \pm 2.6 \mathrm{a}$ & $5.06 \pm 0.04 \mathrm{ab}$ & 4.93 \\
\hline & M2 & $\mathrm{Ab}$ & 3 & 100 & $97.4 \pm 2.6 \mathrm{a}$ & $6.47 \pm 0.05 \mathrm{a}$ & 6.30 \\
\hline & M2 & Ad & 1 & 100 & $81.0 \pm 1.7 \mathrm{ab}$ & $2.93 \pm 0.05 \mathrm{bc}$ & 2.37 \\
\hline & M2 & Ad & 2 & 100 & $75.2 \pm 0.3 \mathrm{bc}$ & $2.42 \pm 0.06 \mathrm{~cd}$ & 1.82 \\
\hline & M2 & Ad & 3 & 100 & $60.0 \pm 0.0 \mathrm{bcd}$ & $1.98 \pm 0.08 \mathrm{cde}$ & 1.19 \\
\hline
\end{tabular}

${ }^{\mathrm{z}}$ Explants were cultured first 3 weeks in the dark and the rest of the time in the light. The values are the means ( \pm SE) of two replicates with 30 explants each. Means within a column within the same cultivar followed by different letters were statistically significant at $P \leq 0.05$ according to Fisher's least significant difference test.

${ }^{y}$ Abaxial leaf surface in contact with the medium.

${ }^{x}$ Adaxial leaf surface in contact with the medium.

"weaves were cut transversely across the midrib into three pieces proximal, middle, and distal designated as 1, 2, and 3, respectively.

TDZ concentrations because we used M2 medium that contained much higher TDZ concentration $(22 \mu \mathrm{M})$. This concentration has not proved detrimental and the majority of shoots regenerated were healthy, green, and morphologically normal (Fig. 1C-F). The hyperhydration was usually reported as a frequent problem during shoot regeneration from leaf explants in many fruit trees, including apple (Dobránszki et al., 2002; Magyar-Tábori et al., 2010), especially if TDZ at higher concentration was used in regeneration medium. In our work, the hyperhydrated shoots were also observed but were not severe and ranged from $5.5 \%$ (M1) to $7.3 \%$ (M2) in 'Golden Delicious' and from $6.8 \%$ (M1) to $11.1 \%$ (M2) in 'Melrose'. The hyperhydrated shoots were discarded and only healthy shoots were transferred to the subsequent multiplication medium.

Effect of regeneration media on subsequent shoot multiplication. Regeneration medium M2 not only had a positive effect on regeneration from leaf explants, but also significantly affected subsequent shoot multiplication (Fig. 3) on SM medium. The shoot multiplication rate in both cultivars was almost twice higher when initially M2 regeneration medium was used compared with M1. This effect was sustained in three subsequent subcultures. These findings were in agreement with the previous reports showing that medium on which source explants were cultured had a significant influence on subsequent regeneration (Antonelli and
Druart, 1990; Burgos and Alburquerque, 2003).

Rooting and acclimatization. Individual adventitious shoots that reached 2 to $3 \mathrm{~cm}$ in length were separated from shoot clusters and placed onto rooting MS media containing IBA or NAA at $0,2.5,5$, or $10 \mu \mathrm{M}$. No roots were induced on PGR-free MS medium. ANOVA indicated that cultivar and medium as well as cultivar $\times$ medium interaction significantly affected the rooting percentage, whereas mean number of roots per shoot and root length are cultivar- and medium-dependent. The highest percentage of root induction $(74.3 \%)$ in 'Golden Delicious' shoots was obtained on the medium initially containing $2.5 \mu \mathrm{M}$ IBA (Table 2), which is in accordance 


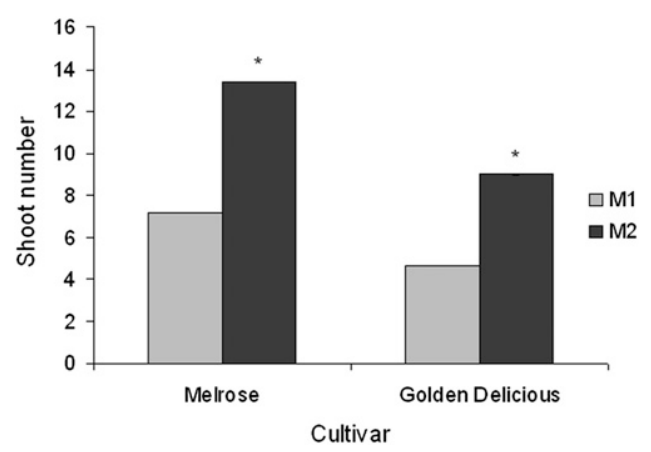

Fig. 3. Effect of M1 and M2 regeneration media on subsequent shoot multiplication after 6 weeks of culture on SM medium containing $2.2 \mu \mathrm{M}$ BA and $0.26 \mu \mathrm{M}$ NAA; data represent mean values ( $\pm \mathrm{SE}$ ) of five replicates with five samples $(\mathrm{n}=25)$ for each treatment. Effect of M1 and M2 media on multiplication within the same cultivar were compared by a $t$ test for dependent samples. $\mathrm{SM}=$ shoot multiplication medium; $\mathrm{BA}=6$-benzylaminopurine; NAA = 1-naphthaleneacetic acid.

Table 2. Effect of different concentrations of auxins, IBA, and NAA added in MS medium on rooting of shoots obtained from leaf explants after 6 weeks of culture.

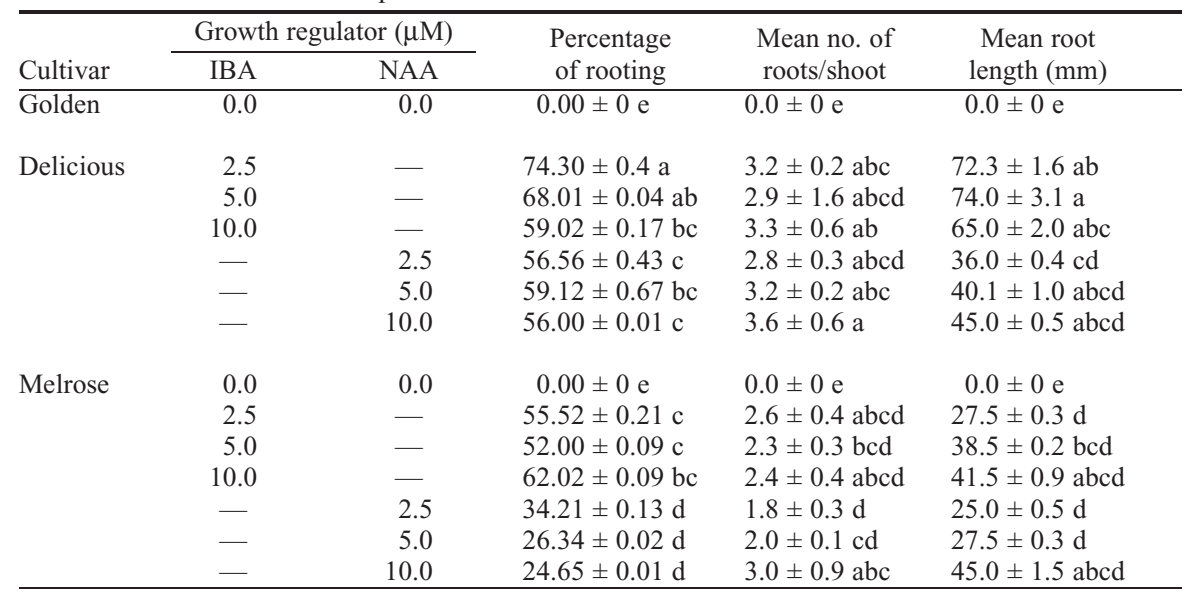

Values represent the mean \pm SE of two replicates with 10 shoots each. Means within a column followed by different letters are statistically significant at $P \leq 0.05$ according to Fisher's least significant difference test.

IBA = indole-3-butyric acid; NAA = 1-naphthaleneacetic acid; MS = Murashige and Skoog

with the earlier reports (Belaizi et al., 1991; Liu et al., 1983; Sriskindarajah et al., 1994) where $65 \%$ to $80 \%$ of rooting was achieved using reduced MS supplemented with $15 \%$ sucrose and 1.5 to $9.8 \mu \mathrm{M}$ IBA. The rooting ability was cultivar-dependent and 'Golden Delicious' was found to be easy to root in vitro (greater than $70 \%$ rooting; reviewed by Dobránszki and Teixeira da Silva, 2010). The rooting percentage decreased as IBA concentration increased, which has also been observed in 'M.26' (Magyar-Tábori et al., 2002), whereas a similar decreasing trend when NAA was used has not been observed (Table 2). In this cultivar, on average, three roots 3.5 to $13.5 \mathrm{~cm}$ long were formed per shoot (Table 2). Otherwise, 'Melrose' could be characterized as moderate to root in vitro, which displayed the highest rooting potential $(62.1 \%)$ on rooting medium containing $10 \mu \mathrm{M}$ IBA, in which an average of 2.4 roots ( 2 to 7 $\mathrm{cm}$ long) were formed per shoot (Table 2). Although auxins and genotype are the most important factors influencing in vitro rooting, cytokinin content of the regeneration media can also significantly affect rooting ability of in vitro apple shoots (Magyar-Tábori et al., 2011; Marin et al., 1993; Webster and Jones, 1991). TDZ, especially at high concentration, is known to inhibit the rooting of regenerated shoots (Magyar-Tábori et al., 2011; van Nieuwkerk et al., 1986). Comparing the rooting potential of shoots regenerated on M1 and M2 media, a nonsignificant difference between them was found and therefore the results of rooting presented in Table 2 are pooled. Additionally, successful rooting results obtained for both cultivars Golden Delicious and Melrose, although they regenerated initially on TDZ-containing media, could be the result of insertion of a 6-weeklong multiplication phase on SM medium containing $2.2 \mu \mathrm{M}$ BA and $0.26 \mu \mathrm{M}$ NAA. The successful rooting and acclimatization after subculture of regenerated shoots on proliferation media and similar rooting rate as micropropagated shoots have already been reported for various apple cultivars (Dufour, 1990; Magyar-Tábori et al., 2011; Yao et al., 1995) and rootstocks (Pawlicki and Welander 1994; Sedira et al., 2001; Zhu et al., 2001).
Plantlets with well-developed roots (Fig. $1 \mathrm{E}-\mathrm{F})$ were successfully acclimatized in pots (Fig. 1G) with a survival frequency of $89 \%$ for 'Golden Delicious' and $74 \%$ for 'Melrose'.

Our results suggest that shoot regeneration from apple leaf explants was highly influenced by genotype, culture medium, explant orientation, and by a combination of these factors. The best regeneration response was obtained when 'Golden Delicious' explants were placed abaxially and 'Melrose' adaxially onto $\mathrm{M} 2$ regeneration medium containing $22 \mu \mathrm{M}$ TDZ and $1.5 \mu \mathrm{M}$ IBA with $0.7 \%$ agar and preincubated in the dark for 3 weeks at the onset of regeneration. Under these conditions, a maximal index of shoot-forming capacity of 11.44 in 'Melrose' and of 6.30 in 'Golden Delicious' was achieved. Moreover, M2 medium significantly increased subsequent shoot multiplication rate.

By optimizing the examined parameters, we were able to improve the regeneration frequency in 'Golden Delicious' and to establish an efficient regeneration protocol in 'Melrose'. This highly efficient regeneration system will be applied toward the development of a genetic transformation protocol aimed at further improvement of disease resistance in these important apple cultivars.

\section{Literature Cited}

Abdollahi, H., R. Muleo, and E. Rugini. 2006 Optimization of regeneration and maintenance of morphogenic callus in pear (Pyrus communis L.) by simple and double regeneration techniques. Sci. Hort. 108:352-358.

Antonelli, M. and P. Druart. 1990. The use of a brief 2,4-D treatment to induce leaf regeneration on Prunus canescens. Acta Hort. 280:45-50.

Belaizi, M., H. Paul, R.S. Sangwan, and B.S. Sangwan-Norreel. 1991. Direct organogenesis from internodal segments of in vitro grown shoots of apple cv. Golden delicious. Plant Cell Rpt. 9:471-474.

Bhatti, S. and G. Jha. 2010. Current trends and future prospects of biotechnological interventions through tissue culture in apple. Plant Cell Rpt. 29:1215-1225.

Burgos, L. and N. Alburquerque. 2003. Low kanamycin concentration and ethylene inhibitors improve adventitious regeneration from apricot leaves. Plant Cell Rpt. 21:1167-1174.

Chevreau, E., F. Mourgues, M. Neve, and M. Chevalier. 1997. Effect of gelling agents and antibiotics on adventitious bud regeneration from in vitro leaves of pear. In Vitro Cell. Dev. Biol. Plant 33:173-179.

Dobránszki, J., K. Magyar-Tábori, E. JámborBenczúr, E. Kiss, J. Lazányi, and T. Bubán. 2002. Effects of conditioning of apple shoots with meta-topolin on the morphogenic activity of in vitro leaves. Acta Agron. Hung. 50:117126.

Dobránszki, J. and J.A. Teixeira da Silva. 2010 Micropropagation of apple-A review. Biotechnol. Adv. 28:462-488.

Dobránszki, J. and J.A. Teixeira da Silva. 2011. Adventitious shoot regeneration from leaf thin cell layers in apple. Sci. Hort. 127:460-463.

Dufour, M. 1990. Improving yield of adventitious shoots in apple. Acta Hort. 280:51-61.

Durham, R.E. and S.S. Korban. 1994. Effects of plant size, pretreatment, and light intensity on 
shoot regeneration from in vitro-grown apple leaves, p. 355-359. In: Schmidt, H. and K. Kellerhals (eds.). Progress in temperate fruit breeding. Kluwer Academic Publishers, Dordrecht, The Netherlands.

Famiani, F., N. Ferradini, P. Staffolani, and A. Standardi. 1994. Effect of leaf excision time and age, BA concentration and dark treatments on in vitro shoot regeneration of M.26 apple rootstock. J. Hort. Sci. 69:679-685.

Fasolo, F., R.H. Zimmerman, and I. Fordham. 1989. Adventitious shoot formation on excised leaves of in vitro grown shoots of apple cultivars. . Plant Cell Tiss. Org. Cult. 16:75-87.

George, E.F. 1993. Factors affecting growth and morphogenesis, p. 231-271. In: George, E.F. (ed.). Plant propagated by tissue culture. Exegetics Ltd., London, UK.

Grafe, C. and G. Wricke. 1998. Increase in vitro regeneration in Malus domestica by the application of phosphatase inhibitors. Plant Breed. 117:563-566.

Herman, D.E. and C.E. Hess. 1963. The effect of etiolation upon the rooting of cuttings. Proc. Intl. Plant Prop. Soc. 13:42-62.

Korban, S.S., P.A. O'Connor, and A. Elobeidy. 1992. Effects of thidiazuron, naphthaleneacetic acid, dark incubation and genotype on shoot organogenesis from Malus leaves. J. Hort. Sci. 67:341-349.

Liu, J.R., K.C. Sink, and F.G. Dennis. 1983. Plant regeneration from apple seedling explants and callus cultures. Plant Cell Tiss. Org. Cult. 2:293304.

Magyar-Tábori, K., J. Dobránszki, and I. Hudák. 2011. Effect of cytokinin content of the regeneration media on in vitro rooting ability of adventitious apple shoots. Sci. Hort. 129:910-913.

Magyar-Tábori, K., J. Dobránszki, E. JámborBenczúr, J. Lazányi, J. Szalai, and A. Ferenczy. 2002. Effects of indole-3-butyric acid levels and activated charcoal on rooting of in vitro shoots of apple rootstocks. Intl. J. Hort. Sci. 8:25-28.

Magyar-Tábori, K., J. Dobránszki, J.A. Teixeira da Silva, S.M. Bulley, and I. Hudák. 2010. The role of cytokinins in shoot organogenesis in apple. Plant Cell Tiss. Org. Cult. 101:251267.

Maheswaran, G., L. Pridmore, P. Franz, and M.A Anderson. 2007. A proteinase inhibitor from Nicotiana alata inhibits the normal development of light-brown apple moth, Epiphyas postvittana in transgenic apple plants. Plant Cell Rpt. 26:773-782.

Marin, J.A., O.P. Jones, and W.C. Hadlow. 1993. Micropropagation of columnar apple trees. J. Hort. Sci. 68:289-297.

Miguel, C.M., P. Druart, and M.M. Oliveira. 1996. Shoot regeneration from adventitious buds induced on juvenile and adult almond (Prunus dulcis Mill.) explants. In Vitro Cell. Dev. Biol. Plant 32:148-153.

Murashige, T. and F. Skoog. 1962. A revised medium for rapid growth and bioassays with tobacco tissue cultures. Physiol. Plant. 15:473497.

Pawlicki, N. and M. Welander. 1994. Adventitious shoot regeneration from leaf segments of in vitro cultured shoots of the apple rootstock Jork 9. J. Hort. Sci. 69:687-696.

Pawlicki-Jullian, N., M. Sedira, and M. Welander. 2002. The use of Agrobacterium rhizogenes transformed roots to obtain transgenic shoots of the apple rootstock Jork 9. Plant Cell Tiss. Org. Cult. 70:163-171.

Predieri, S. and F.M. Fasolo. 1989. High-frequency shoot regeneration from leaves of the apple rootstock M26 (Malus pumila Mill.). Plant Cell Tiss. Org. Cult. 17:133-142.

Sedira, M., A. Holefors, and M. Welander. 2001. Protocol for transformation of the apple rootstock Jork 9 with the rolB gene and its influence on rooting. Plant Cell Rep. 20:517-524.
Seong, E.S. and K.J. Song. 2008. Factors affecting the early gene transfer step in the development of transgenic 'Fuji' apple plants. Plant Growth Regulat. 54:89-95.

Smolka, A., M. Welander, P. Olsson, A. Holefors, and L.H. Zhu. 2009. Involvement of the ARRO-1 gene in adventitious root formation in apple. Plant Sci. 177:710-715.

Sriskindarajah, S., P.B. Goodwin, and J. Speirs. 1994. Genetic transformation of the apple scion cultivar 'Delicious' via Agrobacterium tumefaciens. Plant Cell Tiss. Org. Cult. 36:317-329.

Theiler-Hedtrich, C. and R. Theiler-Hedtrich. 1990. Influence of TDZ and BA on adventitious shoot regeneration from apple leaves. Acta Hort. 280:195-199.

Van Nieuwkerk, J.P., R.H. Zimmerman, and I. Fordham. 1986. Thidiazuron stimulation of apple shoot proliferation in vitro. HortScience 21:516 518.

Viršček-Marn, M., B. Bohanec, and B. Javornik. 1999. Adventitious shoot regeneration from apple leaves: Optimisation of the protocol and assessment of genetic variation among regenerants. Phyton (Horn) 39:61-70.

Webster, C.A. and O.P. Jones. 1991. Micropropagation of some cold-hardy dwarfing rootstocks for apple. J. Hort. Sci. Biotechnol. 66:1-6.

Yao, J.L., D. Atkinson, R. Richardson, and K. Morris. 1995. Regeneration of transgenic plants from the commercial apple cultivar Royal Gala. Plant Cell Rpt. 14:407-412.

Yepes, L.M. and H.S. Aldwinckle. 1994. Factors that affect leaf regeneration efficiency in apple, and effect of antibiotics in morphogenesis. Plant Cell Tiss. Org. Cult. 37:257-269.

Zhu, L.H., A. Holefors, A. Ahlman, Z.T. Xue, and M. Welander. 2001. Transformation of the apple rootstock M.9/29 with rolB gene and its influence on rooting and growth. Plant Sci. 160:433-439. 